\title{
Adolescents' Experiences of Participating in a Weight-loss Programme, Linked to Weight Status, Health-related Quality of Life and Self-concept: A Longitudinal Study
}

\author{
${ }^{1}$ Department of Paediatrics, Regional Hospital Viborg, Denmark \\ ${ }^{2}$ Centre for Research in Clinical Nursing, Denmark \\ ${ }^{3}$ Department of Public Health, Section for Nursing, Aarhus University, Aarhus C, Denmark \\ ${ }^{4}$ Faculty of Health, The School of Nursing and Midwifery, Deakin University, Australia
}

Marianne EG 1,2,3*, Kirsten Frederiksen³ ${ }^{3}$ Marianne Vamosi ${ }^{3}$ and Vibeke Lorentzen 1,2,4

${ }^{*}$ Corresponding author: Marianne EG, Department of Paediatrics, Regional Hospital Viborg, Denmark;the Centre for Research in Clinical Nursing, Denmark, Tel: +45 78445406; E-mail: marianne.eg@midt.rm.dk

Received date: December 10, 2018; Accepted date: February 05, 2019; Published date: February 12, 2019

Citation: Marianne EG, Kirsten F, Marianne V, Vibeke L (2019) Adolescents' Experiences of Participating in a Weight-loss Programme, Linked to Weight Status, Health-related Quality of Life and Self-concept: A Longitudinal Study. J Child Obes Vol No 4 Iss No: 1:001.

Copyright: (C2019 Marianne EG, et al. This is an open-access article distributed under the terms of the Creative Commons Attribution License, which permits unrestricted use, distribution, and reproduction in any medium, provided the original author and source are credited.

\section{Abstract}

Purpose: To investigate the link between adolescents' experiences of participating in a weight-loss programme and their weight status, Health-Related Quality of Life and selfconcept over 5 years.

Design and Method: A qualitative study with a hermeneutic approach, focused on interpreting adolescents' experiences. Interviews of 10 adolescents in a weight-loss programme, and their parents, three times over 5 years. The interview findings were supported by BMI-SDS (Body Mass Index standard deviation scores) and questionnaires: HealthRelated Quality of Life (HRQOL), and self-concept (Beck Youth Inventories, BSCI-Y).

Results: Immediately after completion of the weight-loss programme, the 10 adolescents had all lost weight and experienced other effects, e.g. more energy, making friends and discovering commonalities, along with improved physical parameters, experienced HRQOL and self-concept. However, weight loss was difficult to maintain after completion. Some adolescents who had regained weight 1 year after completion reported lower perceived $\mathrm{HRQOL}$ and self-concept and also left the study.

Conclusion: Weight loss can be achieved during a treatment programme for overweight adolescents, bringing lower BMI and also potential psycho-social benefits. Focus on weight loss alone may involve overlooking other positive sideeffects of the treatment. There are also overlooked negative effects: Not all participants maintained weight loss, and for regainers, some $\mathrm{HRQOL}$ and self-concept scores deteriorated, compared to their situation pre-programme. These negative effects are not described in other studies.

Practice Implications: We encourage enhanced professional support for drop-outs and regainers, and we recommend ongoing, open-ended programmes to better retain and support adolescents and their families. Our findings indicate this would improve intervention outcomes for the entire group.

Keywords: Adolescents; Health-related quality of life; Self-concept; Interviews; Obesity

\section{Introduction}

In this article, we report on the links between how adolescents experience participating in a 1-year weight-loss programme, and the effect of this participation in the long term (over a period of 5 years after completing the weight-loss programme itself). Several studies have already shown that multidisciplinary treatments are effective in reducing BMI and also improve Health-Related Quality of Life (HRQOL) and selfconcept while they are under way, i.e. in the short term and during the project period $[1,2]$. However, we know that it is difficult to maintain reduced $\mathrm{BMI}[3,4]$.

The prevalence of obesity has reached critical levels worldwide, and childhood obesity is one of the gravest publichealth challenges of the $21^{\text {st }}$ century [5]. This group suffers severe medical consequences, which can lead to long-term health problems $[6,7]$. Short-term psycho-social problems such as discrimination, stigmatisation, teasing, bullying and depression also affect adolescents in this group, as emphasised in numerous studies [8-10]. Furthermore, adolescents with overweight often experience lower quality of life, social and emotional problems, and negative body self-image. This can cause lower expectations to their own academic achievement, and thereby fewer years of education, leading in turn to lower future job status than that of their normal-weight peers [9]. 
Previous research on quality of life has demonstrated that adolescents with obesity are challenged by reduced HRQOL $[8,10,11]$, reporting lower HRQOL scores than non-obese children. Their scores are comparable to the reported HRQOL of children with chronic diseases and health issues such as asthma, cancer and cardiac conditions [12,13]. In the treatment of childhood and adolescent obesity, reported HRQOL scores are used as an important measure because the HRQOL scale includes psycho-social issues and medical consequences, rather than just quantitative data such as BMI.

Even so, generally speaking, a weight-loss programme's efficacy, and thus its success, is often measured based solely on BMI reduction, which is frequently the stated aim for participants in a treatment programme. Kolotourou et al. state that BMI should not be the sole threshold value from which to determine whether an intervention has been successful, as several important health parameters indicate that benefits such as better glucose and lipid profiles and positive metabolic effects can be achieved with even a slight reduction in BMI [14]

Research has shown that adolescents with overweight can reduce $\mathrm{BMI}$ and improve their perceived $\mathrm{HRQOL}$ in the short term, but also that maintaining reduced BMI is difficult $[3,4]$. There is, however, a lack of knowledge about the long-term effects of weight-loss treatment on the lives of the adolescents who received it. Too little is known about how adolescent participants in weight-loss treatment behave later in life, both in relation to $\mathrm{BMI}$ and to experienced $\mathrm{HRQOL}$ and self-concept.

Thus, in this study our aim was to investigate what outcomes adolescents had over a period of 5 years after participating in an obesity treatment programme. We investigated this by examining adolescents' experiences and how weight loss related to the participating adolescents' experienced HRQOL and selfconcept, including self-perceptions such as competence, potency, and positive self-worth.

\section{Methods}

This study combined multiple methods of gathering data. We collected qualitative data during interviews with families who participated in a weight-loss programme, and collected quantitative data by measuring the adolescent participants' weight over time, and asking them to fill out questionnaires on HRQOL and self-concept. We used this form of methodological triangulation to gain greater insight into the topic of our study.

Bekhet and Zauszniewski has described methodological triangulation as beneficial for providing confirmation of findings, more comprehensive data, increased validity and enhanced understanding of a topic or phenomenon [15]. In this study we have used both qualitative and quantitative data to understand how adolescents experience participating in a weight-loss programme, compared to the outcomes they actually show in terms of weight and HRQOL measurements.

This study is based on data from the Danish weight-loss treatment programme "ROS 2010", which was a multidisciplinary, family-based programme. Three general goals were set for the participants (adolescents): Weight loss, enjoyment, and satisfaction when engaging in physical activity. The programme consisted of dietary changes, more physical activity than usual, regular weight checks, and motivational conversations. The ROS 2010 programme was run by a multidisciplinary team which included the following professionals: Physicians and nurses, a dietician, a psychologist, a secretary, a physiotherapist, and a sports consultant.

The year-long programme included cooking classes organised for the participating families, who would work along with the ROS dietician and prepare meals according to the nutritional principles recommended in the programme. Group sessions with a psychologist, organised separately for the adolescents and the parents, were held twice during the programme. Each adolescent also had to participate in structured physical activities called "ROS sports" twice a week, and at the end of the programme all of the adolescents were invited to take part in a group trip abroad to a sports and fitness resort on the island of La Santa, off Lanzarote (Figure 1).

\section{Design}

The study design consists of two stages. First, in stage one, the interviews with the adolescents and their parents were conducted and analysed. Then in stage two, the interpretation process, measurements and scores from the adolescents were incorporated so we could learn how their experiences correlated with their scores on quality of life and self-concept. The overall approach of the study was hermeneutic, in accordance with Gadamer's description of philosophical hermeneutics, in which the key elements are understanding and interpretation [16]. By gathering knowledge about the participants' experiences as well as their specific measurements, the study gave us the opportunity to understand the individual parts in order to better understand the context and thus understand the entire picture, in a process which can be compared with what Gadamer HG describes as "the hermeneutic circle" [16].

In the hermeneutic tradition, the concepts of "prejudice" and "pre-understanding" play an important role. Gadamer argued that prejudice is inevitable and indispensable [16]. The author group's nursing knowledge and experience, combined with the knowledge we gathered from the literature about the subject and from group discussions, has formed the pre-understanding behind this study. Because of the long study period, from 2010 to 2015 , our pre-understanding has developed and shifted as we gained new insights and came to understand parts of the process. One example is when the first author, who conducted all the interviews, experienced how difficult it was in the pilot interview to ask directly about the overweight, and to find appropriate wording when speaking with the family about this topic. When we asked families after the interview how they had experienced the interview and the wording used, they responded that it was no problem for them, and that they had expected it since they were participating in a weight-loss programme.

This experience from the pilot interview was significant to the ultimate wording of the guide for the first interview, which came 
to include more direct questions about the issue of overweight, and which came to use of the word "overweight".

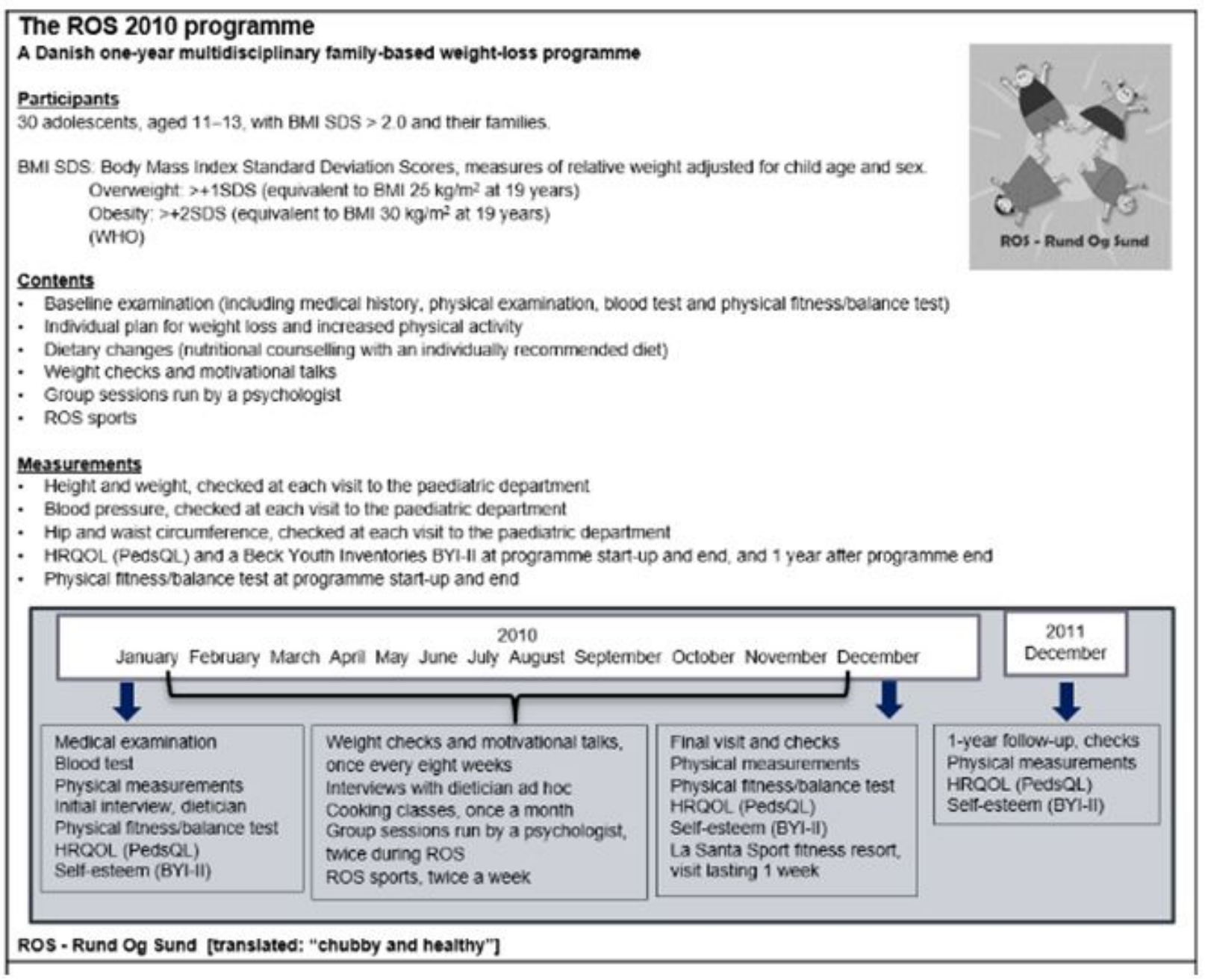

Figure 1: A Danish one-year multidisciplinary family-based weight loss programme.

\section{Interviews}

To gain insight into the participants' experiences in being part of the programme, we used the Qualitative Research Interview [17]. To enable long-term follow-up, we conducted three interviews spread across 5 years. The interviews followed Kvale and Brinkmann's seven-stage interview process: Thematising, designing, interviewing, transcribing, analysing, verifying and reporting [17]. In designing the interviews, we made adaptations appropriate for the adolescents' ages and knowledge levels, bearing in mind the anticipated development occurring over the study's 5-year duration. We intentionally avoided making the child-directed language overly ambitious or overly simplified, and we sought to avoid adult metaphors that could cause misunderstandings. Other researchers have pointed out the importance of being aware of this element when conducting interviews with children or adolescents $[17,18]$.

Each interview session was structured as follows: First, the adolescent was interviewed alone; then the parent(s) alone; then finally the family together. Each interview was conducted according to a semi-structured interview guide.

The first interview guide (used at the end of ROS) focused on the family's experiences during, or just after, ROS 2010, and on what they thought would be most challenging after their participation in ROS 2010 had ended. The second interview guide (used 1 year after ROS) focused on developments during the year that followed the family completed ROS 2010. The third interview guide (used 5 years after ROS) focused on developments during a prolonged period after the family completed ROS 2010.

The following questions are examples from the third interview guide:

- What did you achieve by participating in ROS 2010?

- As far as maintaining weight loss is concerned, how did it go after the treatment ended?

- What did you find most important about taking part in ROS 2010 ? 


\section{Measurements}

To investigate the links between how the adolescents experienced their participation in the programme and their weight status, HRQOL and self-concept, we included each participant's BMI SDS; self-reported HRQOL (PedsQL) [19]; and self-concept, Beck Youth Inventories, BYI-II, for children and adolescents (part BSCl-Y) [20]. Figure 2 describes PedsQL and $\mathrm{BSCl}-\mathrm{Y}$ scoring.
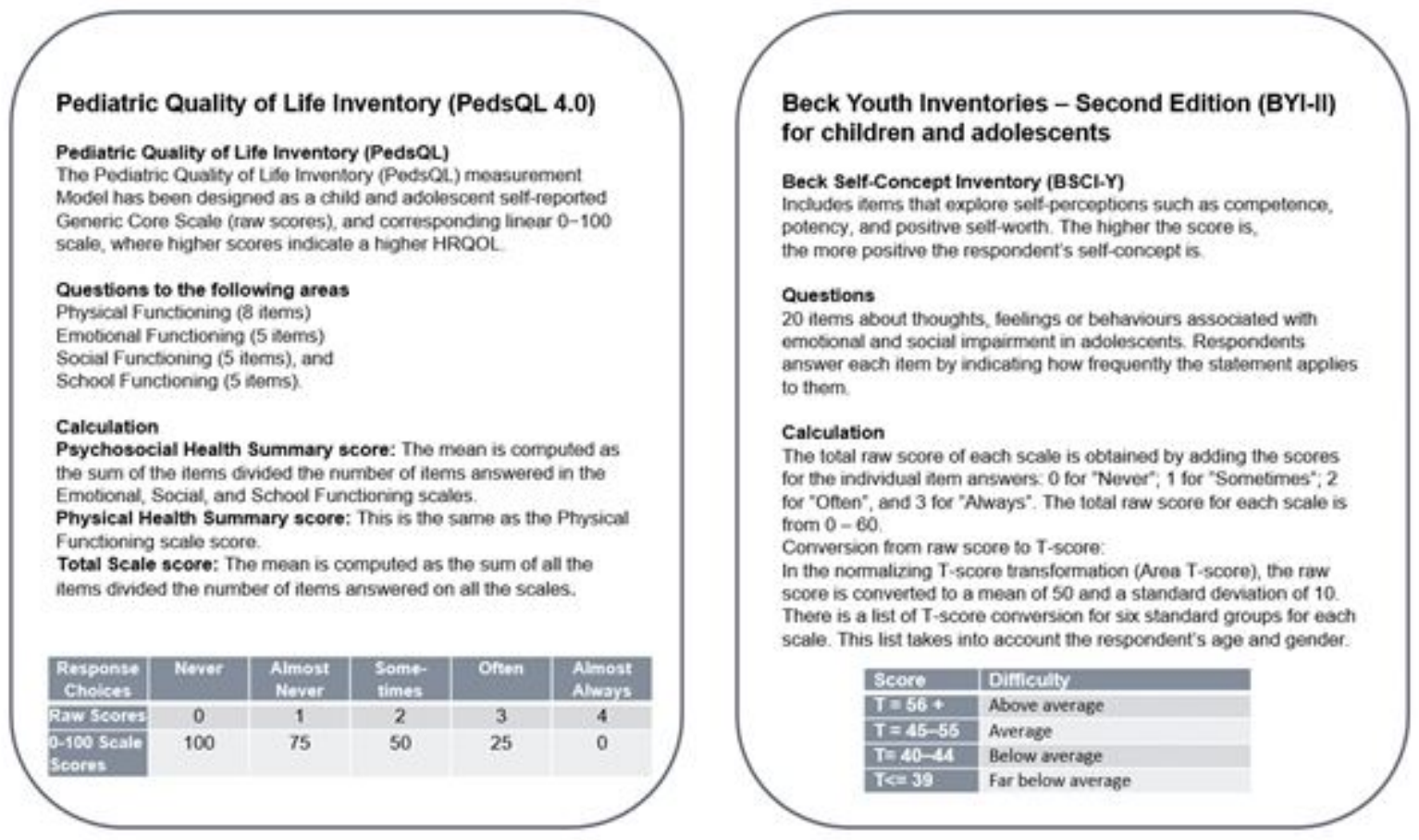

Figure 2: PedsQL and $\mathrm{BSCl}-\mathrm{Y}$ scoring.

BMI-SDS, PedsQL and BSCl-Y were used as measuring tools in ROS 2010 at programme start-up and end, and also 1 year after the programme ended. In this study, we chose to repeat the measurements in conjunction with the interview done 5 years after the programme ended. The results and activities are appear in Table 1 and Figure 3.

Table 1: Measuring tools in ROS 2010 at programme by using BMI-SDS, PedsQL and BSCI-Y.

\begin{tabular}{|c|c|c|c|c|c|c|}
\hline \multicolumn{7}{|c|}{ Presentation of the participants } \\
\hline \multirow[b]{2}{*}{ Ref No } & \multirow[b]{2}{*}{ Description of primary participants and family } & \multirow[b]{2}{*}{ Measurements } & Jan-10 & Dec-10 & Dec-11 & Sep-15 \\
\hline & & & Start of ROS & Interview $1^{*}$ & Interview $2^{*}$ & Interview $3^{*}$ \\
\hline \multirow{6}{*}{1} & Boy, 11 years at start of ROS & & & $A+M+F$ & $A+M+F$ & $A+M+F$ \\
\hline & & BMI SDS & 2.16 & $1.28(-0.88)$ & $1.71(-0.45)$ & $1.98(-0.18)$ \\
\hline & Parents: Live together & PedsQL: Physical & 87.5 & $87.5(0.0)$ & $100.0(+13.7)$ & $93.8(+6.3)$ \\
\hline & Brother & PedsQL: Psycho-social & 80 & $76.6(-3.4)$ & $83.0(+3.0)$ & $86.7(+6.7)$ \\
\hline & & PedsQL: Total & 81.9 & $79.4(-2.5)$ & $87.3(+5.4)$ & $89.1(+7.2)$ \\
\hline & & $\mathrm{BSCl}-\mathrm{Y}$ & 50 & $51(+1)$ & $46(+4)$ & $55(+5)$ \\
\hline \multirow{5}{*}{2} & Boy, 11 years at start of ROS & & & $A+M+F$ & $A+M+S T$ & No interview \\
\hline & & BMI SDS & 3.47 & $2.51(-0.96)$ & $3.26(-0.21)$ & - \\
\hline & Parents: Split up & PedsQL: Physical & 84.4 & $87.5(+3.1)$ & $78.1(-6.3)$ & - \\
\hline & Brother & PedsQL: Psycho-social & 90 & $90.0(0.0)$ & $73.0(-17.0)$ & - \\
\hline & & PedsQL: Total & 88.6 & $89.4(+0.8)$ & $74.5(-14.0)$ & - \\
\hline
\end{tabular}




\begin{tabular}{|c|c|c|c|c|c|c|}
\hline & & BSCI-Y & 61 & $60(-1)$ & $44(-17)$ & - \\
\hline \multirow{6}{*}{3} & Girl, 12 years at start of ROS & & & $A+M+F$ & $A+M+F$ & $A+F$ \\
\hline & & BMI SDS & 2.62 & $2.22(-0.4)$ & $1.61(-1.01)$ & $0.72(-1.9)$ \\
\hline & Parents: Split up & PedsQL: Physical & 65.5 & - & $87.5(+22)$ & $71.9(+6.4)$ \\
\hline & Brother & PedsQL: Psycho-social & 43.3 & - & $65.0(+21.7)$ & $68.3(+25)$ \\
\hline & & PedsQL: Total & 48.9 & - & $70.6(+21.7)$ & $69.6(+20.7)$ \\
\hline & & BSCl-Y & 36 & - & $50(+14)$ & $42(+6)$ \\
\hline \multirow{6}{*}{4} & Boy, 13 years at start of ROS & & & $A+M+F$ & $A+F$ & $A+M$ \\
\hline & Parents: Live together & BMI SDS & 3.28 & $0.85(-2.43)$ & $1.02(-2.26)$ & $1.24(-2.04)$ \\
\hline & No siblings & PedsQL: Physical & 65.5 & - & $93.8(+28.3)$ & $93.8(+28.3)$ \\
\hline & & PedsQL: Psycho-social & 65 & - & $95.0(+30.0)$ & $73.3(+8.3)$ \\
\hline & & PedsQL: Total & 65 & - & $94.7(+29.7)$ & $80.4(+15.4)$ \\
\hline & & BSCI-Y & 33 & - & $73(+40)$ & $62(+29)$ \\
\hline \multirow{6}{*}{5} & Girl, 13 years at start of ROS & Interview participants & & $A+M$ & $A+M$ & No interview \\
\hline & & BMI SDS & 2.73 & $2.28(-0.45)$ & $2.55(-0.18)$ & - \\
\hline & Parents: Live together & PedsQL: Physical & 93.8 & - & $81.3(-12.5)$ & - \\
\hline & Sister & PedsQL: Psycho-social & 68.3 & - & $90.0(+21.7)$ & - \\
\hline & & PedsQL: Total & 74.7 & - & $87.6(+12.9)$ & - \\
\hline & & BSCI-Y & 41 & - & $47(+6)$ & - \\
\hline \multirow{6}{*}{6} & Boy, 10 years at start of ROS & & & $A+M+F$ & $A+M+F$ & $A+M$ \\
\hline & & BMI SDS & 2.54 & $2.00(-0.54)$ & $2.00(-0.54)$ & $2.35(-0.35)$ \\
\hline & Parents: Live together & PedsQL: Physical & 78.1 & $78.1(0.0)$ & $93.8(+15.7)$ & $78.1(0.0)$ \\
\hline & Two brothers & PedsQL: Psycho-social & 75 & $85.0(+10)$ & $91.7(+15.7)$ & $81.7(+6.7)$ \\
\hline & & PedsQL: Total & 75.8 & $83.3(+7.5)$ & $92.2(+16.4)$ & $80.4(+4.6)$ \\
\hline & & BSCI-Y & 27 & $55(+18)$ & $70(+43)$ & $52(+25)$ \\
\hline \multirow{6}{*}{7} & Girl, 11 years at start of ROS & & & $A+M$ & $A+M$ & $A+M$ \\
\hline & & BMI SDS & 2.54 & $2.32(-0.22)$ & $2.36(-0.18)$ & $2.37(-0.17)$ \\
\hline & Parents: Split up & PedsQL: Physical & 78.1 & $87.5(+9.4)$ & $75.0(-3.1)$ & $75.0(-3.1)$ \\
\hline & Sister & PedsQL: Psycho-social & 88.3 & $83.3(-5.0)$ & $76.7(-11.6)$ & $71.7(-16.6)$ \\
\hline & & PedsQL: Total & 86.3 & $84.4(-1.9)$ & $76.3(-10.0)$ & $72.8(-13.5)$ \\
\hline & & BSCI-Y & 46 & $62(+16)$ & $41(-5)$ & $66(+20)$ \\
\hline \multirow{6}{*}{8} & Boy, 12 years at start of ROS & & & $A+M$ & $A+M$ & $A+M$ \\
\hline & & BMI SDS & 2.92 & $2.38(-0.54)$ & $2.85(-0.07)$ & $2.40(-0.52)$ \\
\hline & Parents: Live together & PedsQL: Physical & 78.1 & $81.3(+3.3)$ & $75.0(-3.1)$ & $100(+21.9)$ \\
\hline & Brother & PedsQL: Psycho-social & 83.3 & $88.3(+5.0)$ & $85.0(+1.7)$ & $95.0(+11.7)$ \\
\hline & & PedsQL: Total & 82 & $86.6(+4.6)$ & $82.5(+0.5)$ & $96.7(+14.7)$ \\
\hline & & BSCI-Y & 51 & $63(+12)$ & $48(-3)$ & $64(+13)$ \\
\hline \multirow{2}{*}{9} & Girl, 13 years at start of ROS & & & $A+M$ & $A+M$ & $A+M$ \\
\hline & Parents: Live together & BMI SDS & 2.43 & $2.06(-0.37)$ & $2.63(+0.20)$ & $2.62(+0.19)$ \\
\hline
\end{tabular}




\begin{tabular}{|c|c|c|c|c|c|c|}
\hline & (incl. grandparents) & PedsQL: Physical & 75 & $93.8(+18.8)$ & $81.2(+6.2)$ & $78.1(+3.1)$ \\
\hline & Brother & PedsQL: Psycho-social & 81.7 & $73.0(-8.7)$ & $73.3(-8.4)$ & $81.7(0.0)$ \\
\hline & & PedsQL: Total & 80 & $78.5(-1.5)$ & $75.3(-4.7)$ & $80.4(+0.4)$ \\
\hline & & BSCl-Y & 54 & $70(+16)$ & $65(+11)$ & $68(+14)$ \\
\hline \multirow{6}{*}{10} & Girl, 11 years at start of ROS & & & $A+M$ & $A+M$ & No interview \\
\hline & & BMI SDS & 3.19 & $2.74(-0.45)$ & $2.94(-0.25)$ & - \\
\hline & Parents: Split up & PedsQL: Physical & 87.5 & $87.5(0.0)$ & $84.4(+3 .-1)$ & - \\
\hline & Sister & PedsQL: Psycho-social & 80 & $81.7(+1.7)$ & $76.6(-3.4)$ & - \\
\hline & & PedsQL: Total & 81.9 & $83.1(+1.2)$ & $78.6(-3.3)$ & - \\
\hline & & BSCI-Y & 42 & $52(+10)$ & $53(+11)$ & - \\
\hline
\end{tabular}

Note: A: Adolescent; M: Mother; F: Father

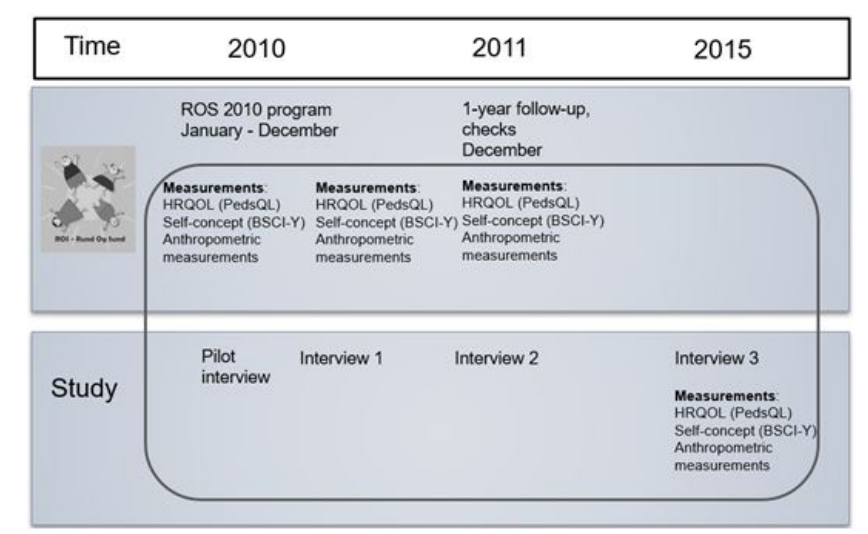

Figure 3: Measuring tools in ROS 2010 at programme by using BMI-SDS, PedsQL and BSCI-Y.

\section{Participants}

\section{The recruitment of participants to the study}

The families who participated in ROS 2010 were informed of the opportunity to participate in this study, with a description stating that participation would involve interviews with the adolescent and the parents three times over a period of 5 years. They were also informed that physical measurements would be taken, as well as tests based on PedsQL and Beck. This would take place twice in addition to the measurements and tests that took place in the ROS 2010 programme.

It was emphasised that participation was voluntary, and that if they did not wish to participate, this would in no way affect their participation in the ROS 2010 programme.

\section{Inclusion/exclusion criteria:}

- Adolescents/families had to be participants in ROS 2010 programme.

- Participants had to be able to understand and speak Danish or English.
- The adolescent and the parents had to wish to participate in the project.

Study participants were included based on the primary participant's (i.e. the adolescent's) score in the BSCI-Y test at programme start-up. The potential participants were split into two groups: One with self-concept scores above average, and one with self-concept scores below or far below average. From each group 5 participants were included, and the 10 selected families were invited to participate. These 10 all accepted. Parental participation in the interviews was a precondition, but having only one parent present was deemed sufficient. Appearance was voluntary, and it varied among the families, and also per family, across the three interviews.

\section{Participants in the study}

Our participant group consisted of 10 adolescents and their parents, selected among the 30 participants in ROS 2010 (Figure 1). The primary participants were aged 11 to 13 when this study began in 2010, all with BMI SDS $>2.0$ (categorized as overweight or obese).

\section{Data collection and measurements}

Interviews: The semi-structured interviews were carried out as shown in Figure 3; We initially did a pilot interview, and interview guides were prepared for each of the three interviews. The pilot interview was conducted to validate the interview guide, and it was conducted with a family who had participated in the ROS 2010 programme, but who were not participants in this study. The pilot interview had been arranged to have the entire family interviewed together. We found it was difficult to get the adolescent to make any statements while the parents were present.

We consequently redesigned and arranged the study interviews so that first the adolescent would be interviewed alone, then the parent(s) alone, then adolescent and parent(s) together. During each actual study interview, the interviewer spoke with the adolescent alone, afterwards with the parent(s) alone, and finally with adolescent and parent(s) together. 
Each study interview lasted 45-60 minutes and was digitally recorded, then transcribed, full-length and verbatim, by the Data Collection Team at the Centre for Research in Clinical NursingViborg, Denmark [21], using Digital Wave Player software and a transcription key.

\section{Measurements}

Among the anthropometric measurements done during ROS 2010, this study used following: Height, weight, and calculation to BMI SDS, which measures relative weight adjusted for the child's age and sex. The data appear in Table 1. Both HRQOL (PedsQL) and $\mathrm{BSCl}-\mathrm{Y}$ are brief to answer, easy to manage, and are designed for children, and both are available in Danish. Through self-reporting, they pass on the respondent's own experienced HRQOL (PedsQL) and self-concept. The nurse instructed each participating adolescent how to fill out the questionnaire, explaining that it was "about how you feel and what you think about your health", further explaining that it was not a test, and that there were no right or wrong answers [19]. $\mathrm{HRQOL}$ (PedsQL) and BSCl-Y scores were calculated according to the guidelines in Figure 2. In both HRQOL (PedsQL) and BSCI-Y, the higher the score, the better the experienced quality of life or self-concept, as applicable.

\section{Analysis}

Our analysis of the interview data were based on the methodology presented by Kvale and Brinkmann, whose principles of qualitative research interviewing focus on the hermeneutic interpretation of meaning in a process that consists of three elements: Meaning coding, meaning condensation, and meaning interpretation [17].

In the meaning-coding phase the empirical material (the transcriptions) was structured using the software tool NVivo v. 10 [22]. After initial read-through (with audio review) of all interviews, the transcriptions were coded, likewise using NVivo. The meaning-condensation phase, which created briefer wording, resulted in themes and sub-themes.

Exhaustive interpretation work then took place in the meaning-interpretation phase. The original text was expanded by adding a hermeneutic layer to understand the meanings embedded in the interview statements. According to Kvale and Brinkmann, the interpretive contexts can be described in terms of three levels: Self-understanding, critical common-sense understanding, and theoretical understanding [17]. To understand the participants' expression of their life-world, we used the measurements of BMI-SDS, HRQOL (PedsQL) and BSCl$\mathrm{Y}$ information obtained from the individual participants in the work done during meaning interpretation.

The use of hermeneutic interpretation, which involves understanding the individual parts in order to reach an understanding of the whole, is carried out as an iterative interpretation process, as described in "the hermeneutic circle" [17].

Table 2 shows an example of how interviews were analysed based on Kvale and Brinkmann's hermeneutic interpretation approach.

Table 2: Contexts of interpreting (including measurements), exemplified.

\begin{tabular}{|c|c|c|c|}
\hline $\begin{array}{l}\text { Theme: Adolescents experiencing } \\
\text { increased well-being }\end{array}$ & Self-understanding & Critical common-sense understanding & $\begin{array}{l}\text { Relation between subjective experiences } \\
\text { and measurements }\end{array}$ \\
\hline \multirow{2}{*}{$\begin{array}{l}\text { B: "Well, I'm much more active, you } \\
\text { know, and in better shape. And that } \\
\text { also means I'm more alert in the } \\
\text { classroom, at school, and more ready } \\
\text { to face the day ahead" (Boy } 4 \text {. } \\
\text { Interview 2, 2011). }\end{array}$} & \multirow{2}{*}{$\begin{array}{l}\text { I am in better shape } \\
\text { and have become } \\
\text { more alert. }\end{array}$} & $\begin{array}{l}\text { The increased physical well-being positively } \\
\text { affects the experience of being in school, and it is } \\
\text { significant in making the adolescent more alert in } \\
\text { class. }\end{array}$ & $\begin{array}{l}\text { BMI SDS dropped from } 3.28 \text { to } 1.28 \text {, from the } \\
\text { start of ROS } 2010 \text { to one year after the end of } \\
\text { the programme. }\end{array}$ \\
\hline & & $\begin{array}{l}\text { The increased physical well-being has an impact } \\
\text { on other parameters for the adolescent's life. }\end{array}$ & $\begin{array}{l}\text { The physical score in PedsQL rose from } 65.5 \\
\text { to } 93.8 \text { and } \mathrm{BSCl}-\mathrm{Y} \text { rose from } 33 \text { to } 73 \text {, } \\
\text { corresponding to an improvement shifting } \\
\text { from far below average to above average for } \\
\text { his age. }\end{array}$ \\
\hline
\end{tabular}

To ensure validity in the process of treating the qualitative interviews, as Kvale and Brinkmann have outlined [17], we applied a transparent process in the sense that all authors read the entire body of interviews and actively contributed to the analytical work.

\section{Ethical Considerations}

Care and consideration are needed when interviewing adolescents and their parents. First, parents must give permission on behalf of their children, and the researcher must also be aware of whether the child wants to participate [23]. Children and adolescents can be very vulnerable, so extra care must be taken to do no harm [24]. In this study, the first author conducted all interviews and could call upon a psychologist from the paediatric department for assistance if any situation arose in connection with the interviews that made such assistance necessary.

Verbal and written consent were obtained prior to the interviews from both the adolescent and the parents, pursuant to the Helsinki Declaration [25]. If the parents were divorced, both parents had to sign the participation agreement in order for the family to participate.

Approval was obtained from the Danish Data Protection Agency (REC no: 2010-41-5420). The Health Research Ethics Committee for the Central Denmark Region indicated that the project did not require notification to be made to this committee (Request 126/2010). Finally, permission was obtained to use PedsQL. 


\section{Results}

In this multi-method study, qualitative data from the interviews helped us to obtain information about how the adolescents had experienced their participation in the ROS 2010 programme. The quantitative data from the measurements supported us in understanding the connection between the adolescents' experiences and the physical measurements of their progress and outcomes. Our findings are presented in the following sections.

\section{Description of Participants}

All adolescents lost weight during the ROS 2010 programme. After 5 years, five had reduced their BMI SDS compared to their starting point, prior to the programme..

\section{Themes}

The analysis revealed central themes related to the purpose of this article, which are presented here:

1. Making friends and feeling good - When adolescents benefit from the weight-loss programme.

2. Regaining weight and dropping out - When adolescents do not benefit in the long term.

Making friends and feeling good-when adolescents benefit from the weight-loss programme: All 10 adolescents in this study said they felt better about their bodies after losing weight during ROS 2010. They felt more energetic and in better physical shape. Several participants spoke of previous negative experiences from gym classes at school, but now expressed feelings of personal achievement at not being the last to cross the finish line when the class had to jog or run. The participants' improved physical condition had also positively influenced their daily life at school. In the words of one boy:

Now I've made friends Well, I'm much more active, you know, and in better shape. And that also means I'm more alert in the classroom, at school, and more ready to face the day ahead. (Boy 4. Interview 2, 2011).

This boy's BMI SDS had dropped from 3.28 to 1.02 in the period from programme start-up to 1 year after the programme ended. His physical PedsQL score rose from 65.5 to 93.8 , and his $\mathrm{BSCl}-\mathrm{Y}$ rose from 33 to 73 , corresponding to a rise in self-concept from a score far below average to above average for his age.

Several participants had experienced feelings of loneliness prior to ROS 2010. Several had changed school multiple times, and some had been bullied and had a hard time making friends.

We found that adolescents in the ROS group formed new relationships that lasted after the programme ended.

One girl described this trend as follows, in the 5-year followup interview:

Now I've made friends. Before, I was fat, and people didn't want to talk to me. They shut me out [of their circles]. But in ROS, I made friends who understood, and we had things in common (Girl 3. Interview 3, 2015).
This girl's BMI SDS had dropped from 2.62 to 0.72 , as measured at the time of the 5-year follow-up interview, and her PedsQL psycho-social health score had risen from 43.3 to 68.3. Also, her $\mathrm{BSCl}-\mathrm{Y}$ rose from 36 (far below average) to 42 (below average).

Several participants described that in meeting adolescents of similar ages and in similarly challenging life situations involving weight problems, they discovered a sense of kinship and commonality. These improved participants' social skills, in some instances leading to more active participation at school, which in turn boosted academic results and promoted greater civic involvement: One was elected to the school's student council; another became the chairman of a political youth organisation; and yet another became a "youth-school ambassador".

Other participants related that they could now spend the night away from home and had formed friendships and relationships with other adolescents and so, for some participants, developments were life-altering in a positive sense.

One boy described it this way:

Well, it's just really meant so much. It's changed everything. If I hadn't been a part of it [the weight-loss programme], then I might still have been overweight today, and it might have got even worse later on. So you could actually say that it's changed my entire life (Boy 4. Interview 3, 2015).

Regaining weight and dropping out-when adolescents do not benefit in the long term: It proved difficult for some of the adolescents to maintain their lower weight, and 3 members from the group dropped out of the study and did not participate in the third interview, for the 5-year follow-up. Therefore we do not know how they have fared in the longer term, after ROS 2010. We do know, however, that all 3 had regained weight, and that some of the reported HRQOL and self-concept scores were already decreasing at the 1-year follow-up interview.

One boy with obesity, who had a BMI SDS of 3.47 at programme start-up, lost enough to move to the category "overweight", with a BMI SDS of 2.51. He described his situation as follows, just after completing the programme:

I've lost weight, so I've gotten smaller, and I also like myself better. I've learned to control my temper, 'cause I wasn't really very good at that before, because they used to call me all sorts of names, and then I'd just get mad (Boy 2. Interview 1, 2010).

This boy's BMI SDS decreased by 0.96 during treatment, and we measured an increase in his physical PedsQL score from 84.4 to 87.5. The boy's PedsQL psycho-social measurement and $\mathrm{BSCl}$ $Y$ were the same before and after ROS 2010 participation. In the first instance, the programme helped this boy improve physically, through weight loss, and he experienced fewer conflicts with his peers. However, when the family took over, and was on its own after ROS 2010 ended, his weight increased to a BMI SDS of 3.26. At the 1-year follow-up interview, the boy stated that:

It's been hard to do it on our own, when there wasn't anybody keeping an eye on you (Boy 2. Interview 2, 2011). 
Coinciding with the regained weight, we saw that the PedsQL physical score dropped (from 84.4 to 78.1), as did the PedsQL psycho-social score (from 90.0 to 73.0). Similarly, the BSCl-Y score fell from above average to below average.

It was not easy for this boy, who explained that his parents were divorced and did not agree on how diet and exercise should be a part of his life. Apparently, as the boy and his parents were no longer accountable to anyone in the ROS 2010 programme, things "went wrong".

Subsequently, the family did not wish to participate in the last interview, as the boy's weight situation had relapsed further. Therefore we have no information on how this boy was faring 5 years after the programme ended. Yet we do know that the boy's HRQOL and BSCI-Y score deteriorated-despite the weight loss he achieved during the programme itself.

\section{Discussion}

In this study, we found that the adolescents in the overweight programme all achieved weight loss, and also reported improvements in physical parameters, experienced HRQOL and self-concept. Several researchers have studied the links between weight loss and improved HRQOL scores, and Steele and Gayes have shown that "clinically significant changes in HRQOL can be detected after only a decrease of about 1 BMI unit (0.998 BMI)" [26].

We saw that being in a context with other programme participants and thereby experiencing a sense of commonality was very important to the adolescents in order to successfully lose weight. We also found that it became difficult to maintain weight loss after group activities ceased and the family did not get support, after the programme ended. Findings from other studies corroborate this, as in Brown et al., which emphasises that "partnerships between patients, families and health care providers" is an important promotive factor in weight-loss programmes [27].

Forging interpersonal relationships and friendships was very important for participants in this study, and Helseth and Misvaer specifically describe relationships and friendships as a crucial element during adolescence [28]. The participants experienced success in forming relationships and taking part in joint activities, such as spending the night at a friend's house or chairing the student council. For adolescents with overweight, such development can be important and indeed, as Grønbæk points out, they experience issues of social isolation, loneliness and lower educational attainment than expected more frequently than their peers do [9].

The adolescents in ROS 2010 were in a developmental phase, transitioning from childhood to adolescence and undergoing huge changes physically, mentally and socially [29]. Antonovsky has described that during this time of life, one develops a "Sense of Coherence" (SOC), which plays a vital role in how, as a person, one is able to manage the crises and challenges that occur in life [30]. In this study, we saw that some adolescents in ROS 2010 became able to manage life events so that life became meaningful for them.
The adolescents described this, for instance, by explaining how, five years after the treatment programme had ended, and the lifestyle changes were no longer on their minds because they had become part of their everyday life. Several of the adolescents forged friendships with others in the programme, and when the programme ended they were able to make friends and invite them home. The adolescents who sustained their weight loss over the period of five years became more independent, and they reported taking responsibility for, and ownership of, their lives.

These developments were beneficial, and they were reflected positively in the reported $\mathrm{HRQOL}$ and self-concept scores of the adolescents.

Our study did, however, have three drop-outs. All three were categorised as obese at the start of the ROS 2010 programme (BMI SDS above 2). This is an overlooked issue, which has not received attention as a relevant point in the described literature. One reported lower experienced scores for both the HRQOL and self-concept after not maintaining weight loss, while the two others scored some of the measurement parameters lower. This worrying development was not discovered or addressed because the ROS 2010 programme itself was limited in time, rather than being open-ended. In other words, even for adolescents who lost weight and felt better about themselves during a programme, participation could lead to lower experienced HRQOL and self-concept if weight loss could not be maintained. DropThe literature has thoroughly described that weight loss and maintenance after weight loss are hard to achieve ((NCD-RisC), 2017). Furthermore, drop-out rates are high in overweight and obesity treatment, sometimes reaching up to $73 \%$ [31]. There is a recognised social inequality to overweight [32], which impacts families that either drop out of the treatment programme or do not maintain weight loss, as they often have few excess resources to manage weight issues on their own, outside or after a programme. Participants can drop out for many reasons, and Rome argues that the child and the parent(s) must be ready to change their lifestyle. Otherwise, as Rome states, interventions can lead to feelings of helplessness, with ongoing dieting attempts and disorder-like eating habits [33]. That is why ending treatment after 1 year is imprudent if the participant is already regaining weight, or if parameters indicate lower HRQOL and self-concept scores. Johansen et al., refer to several international medical associations that recommend classifying overweight as a chronic disease [34]. Doing so could be an important step in running open-ended treatment programmes, rather than programmes ending at a certain date. This would enable ongoing treatment and follow-up similar to that for adolescents with diabetes, asthma and similar chronic diseases and conditions. Furthermore, attention could be targeted to reach participants categorised as obese. Thus, this study showed that if this group did not succeed in maintaining weight loss, their PedsQL and self-concept parameters were lower than before they started on the programme. Kumar and colleagues moreover state that those with poor response to interventions in primary care and with significant health risks should be managed by a multidisciplinary team with expertise in childhood obesity [7]. 
Many treatment programmes are evaluated based on their efficacy in reducing $\mathrm{BMI}$, and we know that even minor physical improvement, for instance a BMI reduction of 10\% (Rome, 2011) or a BMI SDS reduction of $0.25[35,36]$, affect health positively. Research shows that up to $70 \%$ of cases of childhood and adolescent overweight persist into adulthood [37]. Research shows that up to $70 \%$ of cases of childhood and adolescent overweight persist into adulthood (NCD-RisC), 2017 [37,38].

Thus, addressing weight issues during childhood and adolescence offers potential future benefits.

\section{Limitations}

Self-reporting "Health-Related Quality of Life" always involves some degree of uncertainty [39]. This study has missing data occurring in some of the PedsQL and BSCl-Y measurements, and it also has a small number of participants. In addition, much can happen in a family's life over 5 years that will influence the child's development and well-being, over and above their participating in a weight-loss programme. Furthermore, recall bias may have influenced the study.

When using tools to measure a subjective concept, it can be difficult to know whether one is actually measuring the intended parameter. The choice to use PedsQL and $\mathrm{BSCl}-\mathrm{Y}$ in this study was made because they were applied in the ROS 2010 programme and therefore enabled us to repeat the measurements 5 years after the treatment offered. As many studies have shown that HRQOL is affected by overweight, it was interesting to investigate the participants' perception of quality of life, which we here had the opportunity to follow over the long term.

\section{Practice implications}

Overweight in adolescents has commanded international attention and is considered a major threat to health, and complications related to obesity have been shown to persist into adulthood. Therefore it is necessary to begin by paying attention to overweight occurring in childhood.

The findings in this study show a need for greater awareness when treating young people with overweight, since they demonstrate uneven levels of success for programme participants. This raises ethical considerations in connection with the adolescents who were unable to maintain weight loss and reported lower HRQOL and self-concept scores than before the treatment programme. This is a particular concern, given that health authorities do not wish for anyone to be adversely affected by their participation in a treatment programme.

Thus, we encourage professionals to pay greater attention to drop-outs and regainers in weight-loss treatment initiatives, which should consequently take the form of ongoing, openended intervention programmes that can retain and support adolescents and their families. This is an important topic that calls for further research in the future.

\section{Conclusions}

In this study, we found that the adolescents in the weight-loss programme all achieved weight loss, while also experiencing other effects such as becoming more energetic and getting in better physical shape, making friends and discovering a sense of kinship and commonality with peers. Furthermore, they reported improvements in physical parameters, experienced HRQOL and self-concept, which are reported as lower by adolescents with overweight than by their normal-weight peers, and which have a bearing on bullying and social relationships. Weight loss can thus be achieved during a treatment programme, and this can bring other benefits besides lower $\mathrm{BMI}$, such as improved well-being, HRQOL, self-concept and social skills. If we therefore focus on weight loss alone, we overlook all the other potential positive side-effects of the treatment.

In addition, however, there are some overlooked negative effects from treatment programmes for children and adolescents with overweight, since not all participants succeed in maintaining their lower weight-which can lead to poorer experienced HRQOL and self-concept than such participants had before entering the programme. When adolescents complete the programme after a year and treatment therefore ends, they have no way of receiving support on an ongoing basis to maintain the weight loss they have achieved.

Against this background, we advocate higher awareness of this latter group's needs, and we advocate sustained, long-term treatments that support adolescents and their families.

\section{References}

1. Griffiths LJ, Parsons TJ, Hill AJ (2010) Self-esteem and quality of life in obese children and adolescents: A systematic review. Int J Pediatr Obes 5: 282-304.

2. Vos RC, Huisman SD, Houdijk EC, Pijl H, Wit JM (2012) The effect of family-based multidisciplinary cognitive behavioral treatment on health-related quality of life in childhood obesity. Qual Life Res 21: 1587-1594.

3. Holm JC (2016) Children and overweight Ingerslev \& A. Printzlau (Edn) Bariatrics in an interdisciplinary perspective. Prevention and treatment of obesity New Nordic Publisher Arnold Busck pp. 175-202.

4. Whitlock EP, Williams SB, Gold R, Smith PR, Shipman SA (2005) Screening and interventions for childhood overweight: A summary of evidence for the US Preventive Services Task Force. Pediatrics 116: e125-e144.

5. WHO (2016) Health topics. Adolescent health.

6. Holm JC, Gamborg M, Neland M, Ward L, Gammeltoft S, et al. (2012) Longitudinal changes in blood pressure during weight loss and regain of weight in obese boys and girls. J Hypertens 30: 368-374.

7. Kumar S, Kelly AS (2017) Review of childhood obesity: from epidemiology, etiology, and comorbidities to clinical assessment and treatment. Mayo Clin Proc 92: 251-265. 
8. Buttitta M, lliescu C, Rousseau A, Guerrien A (2014) Quality of life in overweight and obese children and adolescents: A literature review. Qual Life Res, 23: 1117-1139.

9. Grønbaek HN, Holm JC (2011) Psychological consequences of severe overweight in teenagers. Ugeskr Laeger 173: 1785-1791.

10. Rees R, Oliver K, Woodman J, Thomas J (2009) Children's views about obesity, body size, shape and weight. A systematic review ( 8 Edn) EPPI-Centre, Social Science Research Unit, Institute of Education, University of London.

11. Wille N, Bullinger M, Holl R, Hoffmeister U, Mann R, et al. (2010) Health-related quality of life in overweight and obese youths: results of a multicenter study. Health Qual Life Outcomes 8: 36.

12. Schwimmer JB, Burwinkle TM, Varni JW (2003) Health-related quality of life of severely obese children and adolescents. JAMA 289: 1813-1819.

13. Varni JW, Limbers CA, Burwinkle TM (2007) Impaired healthrelated quality of life in children and adolescents with chronic conditions: A comparative analysis of 10 disease clusters and 33 disease categories/severities utilizing the PedsQL 4.0 Generic Core Scales. Health Qual Life Outcomes 5: 43.

14. Kolotourou M, Radley D, Chadwick P, Smith L, Orfanos S, et al. (2013) Is BMI alone a sufficient outcome to evaluate interventions for child obesity? Child Obes 9: 350-356.

15. Bekhet A, Zauszniewski JA (2012) Methodological triangulation: An approach to understanding data. Nurse Res 20: 40-43.

16. Gadamer HG (2004) Elements of a theory of hermeneutic experience. Gadamer HG (Edn), Truth and Method (Revised second Edn). Bloomsbury pp: 278-397.

17. Kvale S, Brinkmann S (2014) InterViews: Learning the craft of qualitative research interviewing ( $3 \mathrm{Edn}$ ), Thousand Oaks, Sage Publications, California.

18. Green S, Hill M (2005) Researching children's experience: methods and methodological issues. S. Greene \& D. Hogan (Edn), Reserching children's experience. Approaches and Methods SAGE Publications, London pp. 1-21.

19. PedsQL (2008) PedsQL 4.0 generic core scales. child and parent reports for young children (ages 5 - 7), children (ages 8 - 12), teens (ages 13-18). (ages 5 - 7), children (ages 8 - 12), teens (ages 13-18).

20. Beck JS, Beck AT, Jolly JB (2004) Beck Youth. Beck Youth Inventories of Emotional \& Social Impairm. Second Edition (BYI-2).

21. Lorentzen V (2008) Research across. Sygeplejersken 20: 56-59.

22. Binderkrantz A, Andersen BL (2011) Guide to NVivo 9 (1 edn). [Guide to NVivo]. Special printing plant Viborg: Hans Reitzel's publishing house.

23. Kjellström S (2014) Research ethics. M. Henricson (Edn), Scientific theory and methodology-from idea to examination. Munksgaard.

24. Greig AD, Taylor J, Mackay J (2007) Doing research with children (2 Edn) A practical guide. Sage London: SAGE.
25. World Medical Association Inc. (2009) Declaration of Helsinki. Ethical principles for medical research involving human subjects. J Indian Med Assoc 107: 403-405.

26. Steele RG, Gayes LA, DaltonWT, Smith C, MaphisL, et al. (2016) Change in health-related quality of life in the context of pediatric obesity interventions: a meta-analytic review. Health Psychol 35: 1097-1109.

27. Brown L, Dolisca SB, Cheng JK (2015) Barriers and facilitators of pediatric weight management among diverse families. Clin Pediatr (Phila) 54: 643-651.

28. Helseth S, Misvaer N (2010) Adolescents' perceptions of quality of life: What it is and what matters. J Clin Nurs 19: 1454-1461.

29. Christie D, Viner R (2005) Adolescent development. BMJ 330: 301-304.

30. Antonovsky A (1979) Health, stress and coping. San Francisco.

31. Skelton JA, Beech BM (2011) Attrition in paediatric weight management: A review of the literature and new directions. Obes Rev 12: e273-e281.

32. Due $\mathrm{P}$, Damsgaard MT, Rasmussen $\mathrm{M}$, Holstein $\mathrm{BE}$, Wardle J, et al. (2009) Socioeconomic position, macroeconomic environment and overweight among adolescents in 35 countries. Int J Obes (Lond) 33: 1084-1093.

33. Rome ES (2011) Obesity prevention and treatment. Pediatr Rev 32: 363-372.

34. Johansen A, Holm JC, Pearson S, Kjaersgaard M, Larsen LM, et al. (2015) Danish clinical guidelines for examination and treatment of overweight and obese children and adolescents in a pediatric setting. Dan Med J 62: C5024.

35. Ford AL, Hunt LP, Cooper A, Shield JP (2010) What reduction in BMI SDS is required in obese adolescents to improve body composition and cardiometabolic health? Arch Dis Child 95: 256-261.

36. Reinehr T (2013) Lifestyle intervention in childhood obesity: changes and challenges. Nat Rev Endocrinol 9: 607-614.

37. Svendsen M, Brixval CS, Holstein BE (2013) Weight status in the first year of life, and overweight at school-entry age. Copenhagen, Danish National Institute of Public Health.

38. Abarca-Gómez L, Abdeen ZA, Hamid ZA, Abu-Rmeileh NM, AcostaCazares B, et al. (2017) Worldwide trends in body-mass index, underweight, overweight, and obesity from 1975 to 2016: A pooled analysis of 2416 population-based measurement studies in $128 \cdot 9$ million children, adolescents, and adults. Lancet 390: 2627-2642.

39. Høgh V, Delmar C, Riahi S, Frederiksen K (2014) Quality of life exemplified through patients living with atrial fibrillation. J Nurs Care 3: 150. 